\title{
Editorial
}

\section{Special issue: Foreign policy and governance in the South African maritime domain}

In the 2000s, when Somali piracy threatened important international trade routes, the global community came together to fight the scourge of piracy and secure sea lines of communication. More recently, irregular migration by sea has become a particularly hot topic for European nations bordering the Mediterranean Sea, while issues around fishing resources and how these are threatened by illegal, unreported and unregulated fishing has also garnered much interest. Indeed, these issues are of critical importance to the many countries that are now looking to the seas for economic opportunities, and in so doing, are concerned for the myriad of often interconnected activities that may threaten the sovereign rights and interests of states.

In this context, it is disturbing that issues surrounding South Africa's maritime domain remain under-explored, particularly given that the country has an extensive coastline and maritime territory, which is the meeting place of two oceans and, as a result, holds an important geostrategic position. South Africa has made a recent push toward harnessing the oceans for the purpose of economic development, poverty alleviation and employment creation under the auspices of Operation Phakisa. This is where existing work has been concentrated. However, there is a need to look at South Africa's conceptualisation of the maritime domain more broadly, as well as to consider and compare South Africa's engagements in maritime security.

Prior to the 2014 launch of Operation Phakisa, a programme of the National Development Plan 2030, South Africa's engagement in this area could be described as mostly outward-looking in nature, in what Otto (2014) describes as a pragmatic foreign policy exercise with the aim of demonstrating a contribution to what were, at the time, important global issues. Since then, South Africa's gaze has turned inward and appears to have remained this way. In the absence - as yet - of its own maritime security strategy, and excepting the Navy's own policies and plans, Operation Phakisa constitutes the country's main focal point of interdepartmental thinking on maritime matters. Extensive statements have been made on the utility of the Blue Economy and South Africa's oceans in particular. The programme has received a fair deal of criticism, amongst other reasons, for showing muted results (Walker, 2018), and for piggy-backing on existing projects and investments to claim these as achievements. Positioning Phakisa in the presidency suggests a priority but also a steep curve to operationalise the initiative, and is thus open to academic study.

The South African Research Chairs Initiative (SARChI) Chair in African Foreign Policy and Diplomacy at the University of Johannesburg and the Security Institute for Governance and Leadership (SIGLA) at Stellenbosch University have thus teamed up 
to create this volume, in which we have brought together some of South Africa's leading voices in the area of maritime security.

Anthoni van Nieuwkerk and Calvin Manganyi set the scene by providing a conceptual framework for South Africa's maritime foreign policy and maritime diplomacy using a themed matrix with socio-economic, security and governance dimensions on the horizontal axis, and the national, continental and global levels of analyses on the vertical axis. In highlighting the gap between South African foreign policy and the maritime domain, they propose a working definition of the concepts 'maritime foreign policy' and 'maritime diplomacy' for the South African context. A synopsis is given of four South African strategic interests for maritime policy against the backdrop of the challenges faced given the country's geopolitical position contextualised within its importance in a regional, continental and global context, concluding that policy implementation is a matter requiring attention.

Following this, Vishal Surbun charts how various domestic and continental policies thread together a framework for a global maritime South African foreign policy, assessing Pretoria's engagement in global and regional fora, notably the Indian Ocean Rim Association (IORA).

Timothy Walker then homes in on the relationship between South Africa and the Southern African Development Community (SADC), vis-à-vis the maritime domain, where he explores South Africa's leadership role, and emphasises the need for greater regionalism.

Lisa Otto explores the security-development nexus, assessing South Africa's approach to its maritime security, and examining Operation Phakisa closely, before concluding that there is an urgent need for a review of South Africa's maritime arena.

Further to this, Francois Vreÿ explores whether Operation Phakisa is the answer, reflecting on the ambitious initiative, with the gist of the discussion being forward-looking towards progress, failures and prospects for achieving government's 2030 maritime aims and objectives. His discussion particularly interrogates whether South Africa's foreign policy is reflected in the myriad Operation Phakisa projects focused on unlocking the oceans as a major resource of South Africa's Blue Economy. His discussion contextualises Operation Phakisa in the wider ocean debate, providing the backdrop for assessing Phakisa's performance within the maritime sector, its actual support of the Blue Economy as well as matters of security.

Finally, within the context of the working definition of foreign policy proposed by Van Nieuwkerk and Manganyi, Michelle Nel and Mark Blaine investigate the role of the South African Navy through a practitioner's lens - not only in the provision of maritime security, but also as a role player in maritime foreign policy, questioning whether it is equipped to perform this latter role.

\section{The Guest Editors}

\section{Lisa Otto and Michelle Nel}

